\title{
Airway Ion Transport on the First Postnatal Day in Infants Delivered Vaginally or by Elective Cesarean Section
}

\author{
EROL A. GAILLARD, NIGEL J. SHAW, HELEN L. WALLACE, NIMISH V. SUBHEDAR, AND \\ KEVIN W. SOUTHERN \\ Liverpool Women's Hospital, Neonatal Unit, Liverpool L8 7SS, U.K. [E.A.G., N.J.S., N.V.S.], and Institute \\ of Child Health, University of Liverpool, Alder Hey Children's Hospital, Liverpool L12 2AP, U.K. \\ [H.L.W., K.W.S.]
}

\begin{abstract}
ABST
To determine airway ion transport in term infants on the first
day of postnatal life, and to test the hypothesis that infants born
without labor have reduced sodium absorption, we measured
nasal potential difference using a modified perfusion protocol
suitable for newborn infants. We examined maximal stable base-
line potential difference, the change after perfusion with $10^{-4} \mathrm{M}$
amiloride $(\Delta$ amil), and the change after perfusion with a zero-
chloride solution $\left(\Delta\right.$ zero $\left.\mathrm{Cl}^{-}\right)$in infants born after elective
cesarean section $(n=21)$ or normal labor ( $n=20)$. Maximal
stable baseline potential difference was not different in the two
cohorts $(-24.0 \mathrm{mV}$, range -9 to $-64 \mathrm{mV}$ versus $-25.5 \mathrm{mV}$,
range -6 to $-44 \mathrm{mV})$. The majority of infants in both cohorts
\end{abstract}
The fetal lung is filled with fluid, secreted by pulmonary epithelial cells through active $\mathrm{Cl}^{-}$transport into the bronchial lumen with water moving along the osmotic gradient (1). Lung fluid production slows in late gestation (2). At the time of birth, changes in airway ion transport facilitate the adaptation to postnatal life and air breathing (3). Chloride ion secretion slows and $\mathrm{Na} / \mathrm{K}$ ATPases in the basal membrane of the pulmonary epithelial cell actively transport $\mathrm{Na}^{+}$out of the cell, creating a transcellular gradient for $\mathrm{Na}^{+}$absorption, mediated through the apical ENaC (4).

The $\mathrm{ENaC}$ is composed of three homologous subunits, $\alpha, \beta$, and $\gamma$, that together form a functional ion channel (5). In the human lung, ENaC expression has been found along the whole of the respiratory tract, from the nasal epithelium to the alveoli $(6,7)$.

Several important findings point to a critical role for the $\mathrm{ENaC}$ in the removal of lung fluid during the later stages of

Received May 23, 2002; accepted September 24, 2002.

Correspondence: Erol A Gaillard, M.D., Neonatal Unit, Liverpool Women's Hospital, Neonatal Unit, Crown Street, Liverpool L8 7SS, U.K.; e-mail: erol.gaillard@1wh-tr.nwest.nhs.uk

Supported by a grant from the Liverpool 'Newborn Appeal' (E.A.G.).

DOI: 10.1203/01.PDR.0000069842.09976.CB showed a substantial fall in potential difference after amiloride perfusion, and there was little capacity for chloride secretion. These results demonstrate a fluid absorptive pattern in the airways on the first postnatal day. In these well infants, the ion transport phenotype was not dependent on the presence or absence of labor. (Pediatr Res 54: 58-63, 2003)
PD, potential difference
Abbreviations
ENaC, epithelial sodium channel
RDS, respiratory distress syndrome

gestation and after birth. Expression of $E N a C$, especially the $\alpha$ subunit, increases in the respiratory tract with advancing gestational age in humans (8). In the animal model, ENaC expression is further increased by administration of antenatal steroids (9). Transgenic knockout mice with the $\alpha E N a C$ gene disrupted die soon after birth from an inability to remove fluid from their lungs (10). ENaC can be effectively blocked by the drug amiloride, which acts as a competitive antagonist to $\mathrm{Na}^{+}$ absorption (11). Instillation of amiloride into the lungs of guinea pigs just before their birth results in severe respiratory distress after delivery (12). Animal studies have demonstrated the importance of lung fluid removal on postnatal adaptation (13). Lambs born immediately after removal of half their lung fluid had significantly improved oxygenation and carbon dioxide clearance in the first few hours after birth compared with a control group.

The processes that determine the change in ion transport pattern at birth are not fully determined. It has been suggested that catecholamines play an important role $(14,15)$. Adrenaline infusion in chronically catheterized fetal lambs results in a switch from lung liquid secretion to absorption (16), and studies of lung liquid flow during normal labor has demon- 
strated a switch to fluid absorption in parallel with a rise in plasma adrenaline (3).

The aim of this study was to examine airway ion transport in infants born at term by either elective cesarean section (without labor) or vaginally after normal labor. The study was designed to test the hypothesis that infants born without normal labor have reduced $\mathrm{ENaC}$-mediated $\mathrm{Na}^{+}$transport in their airways on the first day of postnatal life. The nasal PD measurement was used to measure airway ion transport.

A PD is generated across airway epithelia through the active transport of charged ions, and the change in PD after perfusion with various solutions gives a relatively noninvasive insight into the various components of airway ion transport. In particular the topical perfusion of amiloride allows characterization of the degree of ENaC-mediated $\mathrm{Na}^{+}$absorption $(17,18)$. In adults nasal PD correlates well with the PD measured in the trachea and distal bronchi $(19,20)$.

A previous nasal PD study of term infants suggested altered airway ion transport in infants born without labor (an increased baseline PD and reduced reduction in PD magnitude after perfusion with amiloride) (21). We used a modified nasal PD protocol, validated for use in infants (18), to further examine the airway ion transport phenotype of well infants on the first day of postnatal life.

\section{METHODS}

This study was approved by the local research ethics committee. Informed consent was obtained antenatally from the parents of all infants in this study.

We tested the hypothesis that birth without labor is associated with reduced $\mathrm{ENaC}$-mediated $\mathrm{Na}^{+}$absorption, resulting in 1) lower maximal stable baseline PDs and 2) reduced responses to amiloride perfusion. We also investigated the capacity of the infant nasal airway epithelium for $\mathrm{Cl}^{-}$secretion.

Subjects. We studied 21 infants delivered by elective cesarean section at term (no labor) and 20 infants delivered vaginally (normal labor) at term. Infants in the normal labor group were recruited during a 4-wk period by approaching parents attending the 20 -wk antenatal booking clinic (if pregnancy and delivery were expected to be normal). Infants for the elective cesarean section group were recruited consecutively on the antenatal ward when mothers were admitted the day before delivery.

Nasal PD measurement. We performed a nasal PD measurement in the first $24 \mathrm{~h}$ after birth. Nasal PD was measured between the nasal epithelium along the floor of the nose of infants and a reference electrode (a sterile butterfly needle with an internal diameter of $0.6 \mathrm{~mm}$ (Venisystems, Abbott, Ireland), filled with $0.9 \% \mathrm{NaCl}$ solution and $3 \%$ agar inserted into the umbilical stump and secured to the cord clamp). The exploring electrode consisted of a single-lumen catheter [polyethylene (PE-10) tubing] threaded over a 30-gauge needle. Three perfusion lines (Silastic tubing, inner diameter, $0.51 \mathrm{~mm}$, outer diameter $0.94 \mathrm{~mm}$; Dow Corning Corp, Midland, MI, U.S.A.) were secured together with a saline bridge into the hub of the 30 -gauge needle. Both catheters are connected to a highimpedance millivolt meter via saline/agar bridges and half-cell calomel electrodes (Accumet Miniature Calomel Reference Electrode; Fisher Scientific, Pittsburgh, PA, U.S.A.). Each nostril was sequentially perfused with an isotonic solution at a rate of $0.1 \mathrm{~mL} \mathrm{~min}{ }^{-1}$, followed by the same solution with amiloride $10^{-4} \mathrm{M}$ added, and finally a zero- $\mathrm{Cl}^{-}$solution with amiloride $\left(10^{-4} \mathrm{M}\right)$.

Infants were loosely swaddled, and a skin PD was obtained to check the reference electrode. Nasal PD was measured at $0.25-\mathrm{cm}$ intervals along the floor of the nose. We identified the point of highest stable PD.

From this point three principal measurements were obtained:

1. Stable maximal baseline PD: This measurement reflects the sum of all the ion transport processes in the airway epithelium during perfusion with an isotonic solution. In older children and adults the predominant airway ion transport processes $\left(\mathrm{Na}^{+}\right.$absorption and anion secretion) render the PD negative when viewed from the lumen. The median time to achieve a stable maximal PD was $50 \mathrm{~s}$ (range, 20-210 s). Occasionally the baseline PD would be drifting up or down, under which circumstance we would not add amiloride until the trace was stable for at least $10 \mathrm{~s}$ (median, $20 \mathrm{~s}$; range, $10-60 \mathrm{~s})$.

2. $\Delta$ amil: This measurement is the response of the PD after addition of amiloride to the isotonic perfusate. As amiloride selectively inhibits $\mathrm{ENaC}$, the reduction in $\mathrm{PD}$ magnitude after amiloride perfusion is a direct reflection of the degree of ENaC-mediated $\mathrm{Na}^{+}$absorption. In addition to the reduction in millivolts, $\Delta$ amil can also be expressed as a percentage of the stable maximal baseline PD.

3. $\Delta$ zero $\mathrm{Cl}$ : Subsequent perfusion of an isotonic solution free of $\mathrm{Cl}^{-}$provides a permissive environment for $\mathrm{Cl}^{-}$secretion and in older children and adults is associated with an increase (hyperpolarization) of the PD (17), which directly reflects the capacity of the epithelium to secrete $\mathrm{Cl}^{-}$. The zero- $\mathrm{Cl}^{-}$solution contains amiloride and is only commenced once the PD has stabilized after amiloride perfusion.

Occasionally the maximal stable baseline PD fluctuated (associated with respiration). The midpoint of the fluctuation was then taken as the maximal stable baseline PD. The median degree of fluctuation was $1 \mathrm{mV}$ (range $0-7 \mathrm{mV}$ ). A single investigator (E.A.G.) performed the measurements and, for logistical reasons, was not blinded to the mode of delivery. The nasal PD tracings were analyzed independently by two investigators, one of whom (K.W.S) was unaware of the gestation and clinical condition of the infant at the time of nasal PD measurement.

Statistical analysis. From previous studies (17, 21), we estimated that a total sample size of 40 infants (20 in each group) would be sufficient to detect a clinically relevant difference of $10 \mathrm{mV}$ in the primary outcome measure (maximal stable baseline PD), with $95 \%$ power at a $1 \%$ significance level. The software program SPSS for Windows 10.0 (SPSS Inc., Chicago, IL, U.S.A.) assisted the analysis. Distribution of the data was analyzed using the Shapiro-Wilk test and by examination of histograms. Comparisons between infants born by cesarean section and vaginal delivery were made using the Mann-Whitney $U$ test (histograms for most variables did not show normal distribution). Spearman's rank correlation coef- 
ficient was used to test for correlation between the continuous variables, time of measurement and stable maximal baseline PD.

\section{RESULTS}

The nasal PD measurement was well tolerated by all infants. The groups were well matched for birth weight and sex; however, gestational age was lower (median, 38 wk versus 40 wk), and the time interval between birth and nasal PD measurement was shorter (median, $6 \mathrm{~h}$ versus $12 \mathrm{~h}$ ) in the elective cesarean section group (Table 1).

There was no significant correlation between the maximal stable baseline PD and the postnatal age at measurement using Spearman's rank correlation $\left(r^{2}=0.08\right.$ for the group as a whole, $p=0.61$; normal labor, $r^{2}=-0.08 ; p=0.74$; no labor, $r^{2}=0.25 ; p=0.28$ ).

The maximal skin PD was not different for the two groups. There was no correlation between the maximal skin PD and maximal stable baseline PD. The clinical course for all infants was unremarkable. No umbilical stump became infected.

Comparison of maximal stable baseline PD values between both nostrils was made using the technique described by Bland and Altman (Bland-Altman plot not shown) (22). The SD of the differences between nostrils was $13 \mathrm{mV}$ with limits of agreement of -29.7 and $23.3 \mathrm{mV}$. There was no statistically significant difference in maximal stable baseline PD values from the first and second nostril (mean difference, $-3.7 \mathrm{mV}$; $95 \%$ confidence interval, -8.7 to $1.3 \mathrm{mV}$ ). Only data from the first nostril measurement are included (Table 2). Representative tracings are shown in Figures 1 and 2.

Median maximal stable baseline PD was $-24.0 \mathrm{mV}$ in the cohort of infants born after elective cesarean section and -25.5 $\mathrm{mV}$ in the normal delivery group. After amiloride perfusion, PD magnitude fell by a median of $19.0 \mathrm{mV}$ in the elective cesarean section group compared with $20.5 \mathrm{mV}$ for the normal delivery group. The median change in PD after perfusion with a zero- $\mathrm{Cl}^{-}$solution was $-1.0 \mathrm{mV}$ in the elective cesarean section group $(n=19)$ and $-2.5 \mathrm{mV}$ in the normal delivery group $(n=20)$. Two infants in the no labor group became unsettled during perfusion with the zero- $\mathrm{Cl}^{-}$solution, and we were unable to obtain satisfactory tracings. The zero- $\mathrm{Cl}^{-}$ element of these tracings was not analyzed.

There was no statistically significant difference between the two groups for any ion transport variable studied.

\section{DISCUSSION}

The results of this study support an absorptive airway ion transport pattern in healthy term infants on the first day of

Table 1. Clinical characteristics of infants*

\begin{tabular}{lccc}
\hline & No labor & Normal delivery & $p$ value \\
\hline $\mathrm{n}$ & 21 & 20 & \\
Male (\%) & $14(67)$ & $10(50)$ & \\
Birth weight (g) & $3700(2180-4540)$ & $3546(2768-4300)$ & 0.39 \\
Gestation (wk) & $38(37-40)$ & $40(38-41)$ & $<0.001$ \\
Age at measurement (h) & $6(3-10)$ & $12(2-22)$ & $<0.001$ \\
\hline * All values given as median (range). Mann-Whitney $U$ test was used for \\
statistical analysis.
\end{tabular}

Table 2. Variables obtained from perfusion studies*

\begin{tabular}{|c|c|c|c|}
\hline & No labor & Normal labor & $\begin{array}{c}p \\
\text { value }\end{array}$ \\
\hline $\begin{array}{l}\text { Maximal stable baseline } \\
\text { PD }(\mathrm{mV})\end{array}$ & $-24.0(-9$ to -64$)$ & $-25.5(-6$ to -44$)$ & 0.99 \\
\hline$\Delta \operatorname{amil}(\mathrm{mV})$ & $19.0(5$ to 56$)$ & 20.5 (5 to 38$)$ & 0.98 \\
\hline$\Delta$ amil $(\%)$ & $-79.0(-50$ to -94$)$ & )$-83.5(-36$ to -100$)$ & 0.59 \\
\hline Residual PD (mV) & $-5.0(-2$ to -11$)$ & $-5.0(0$ to -20$)$ & 0.88 \\
\hline$\Delta$ zero $\mathrm{CI}^{-}(\mathrm{mV})$ & $-1.0(6$ to -23$)$ & $-2.5(4$ to -22$)$ & 0.54 \\
\hline Maximal skin PD (mV) & $-31.0(-13$ to -54$)$ & )$-33.0(-15$ to -57$)$ & 0.47 \\
\hline
\end{tabular}

* All values given as median (range). Statistical analysis was performed using Mann-Whitney $U$ test.

postnatal life. They do not support the hypothesis that infants born without labor have reduced $\mathrm{ENaC}$-mediated $\mathrm{Na}^{+}$ transport.

An increased incidence of RDS and transient tachypnea of the newborn has been described in term infants delivered by elective cesarean section before the onset of labor (23). This has been attributed to delayed lung fluid removal in those infants (24). When lung volumes in term infants soon after birth after no labor were compared with those of infants born after normal vaginal delivery, the most striking difference was significantly reduced total lung volumes in the no labor group despite similar thoracic circumference (25). The authors concluded that an increased lung liquid volume with decreased gas component may be the reason for these findings. The respiratory rates between the groups were not different.

Gowen and colleagues (21) reported a significant difference in mean baseline PD (which corresponds to our maximal stable baseline PD) between infants born at term after normal labor (mean, $-19.7 \mathrm{mV}$ ) compared with infants born after no labor (mean, $-27.7 \mathrm{mV}$ ) on the first day of postnatal life. This mean baseline PD was higher still in infants with raised respiratory rates (mean, $-29.6 \mathrm{mV}$ ) and was associated with a reduced reduction in PD magnitude in response to amiloride perfusion. The fall in PD after perfusion with amiloride $\left(10^{-5} \mathrm{M}\right)$ was less than $40 \%$ in all groups on the first postnatal day. The authors speculated that these findings might reflect ongoing chloride secretion or amiloride-insensitive sodium absorption.

Barker et al. (26) reported lower maximal PD values in infants of less than $30 \mathrm{wk}$ gestation with RDS compared with non-RDS infants (mean, -16.5 versus $-22.5 \mathrm{mV}$ ). Infants with RDS also had significantly reduced inhibition of amiloride-sensitive $\mathrm{ENaC}$-mediated $\mathrm{Na}^{+}$transport compared with non-RDS infants (29.5\% inhibition versus $38.6 \%)$. Again the authors speculate that these results indicate an incomplete switch from a secretory to a fluid-absorbing airway epithelium. The latter study also found higher maximal PDs with increased gestation, suggesting increased $\mathrm{ENaC}$-mediated sodium transport in more mature infants.

In this study, maximal stable baseline PDs in the no labor group are lower (median, $-24.0 \mathrm{mV}$ ) compared with those reported by Gowen et al. (21); however, we found higher PDs in the group experiencing normal labor (median, $-25.5 \mathrm{mV}$ ).

We also found the range of maximal stable baseline PD values to be wide in both cohorts, suggesting variability in ENaC-mediated $\mathrm{Na}^{+}$transport on the first postnatal day. This 


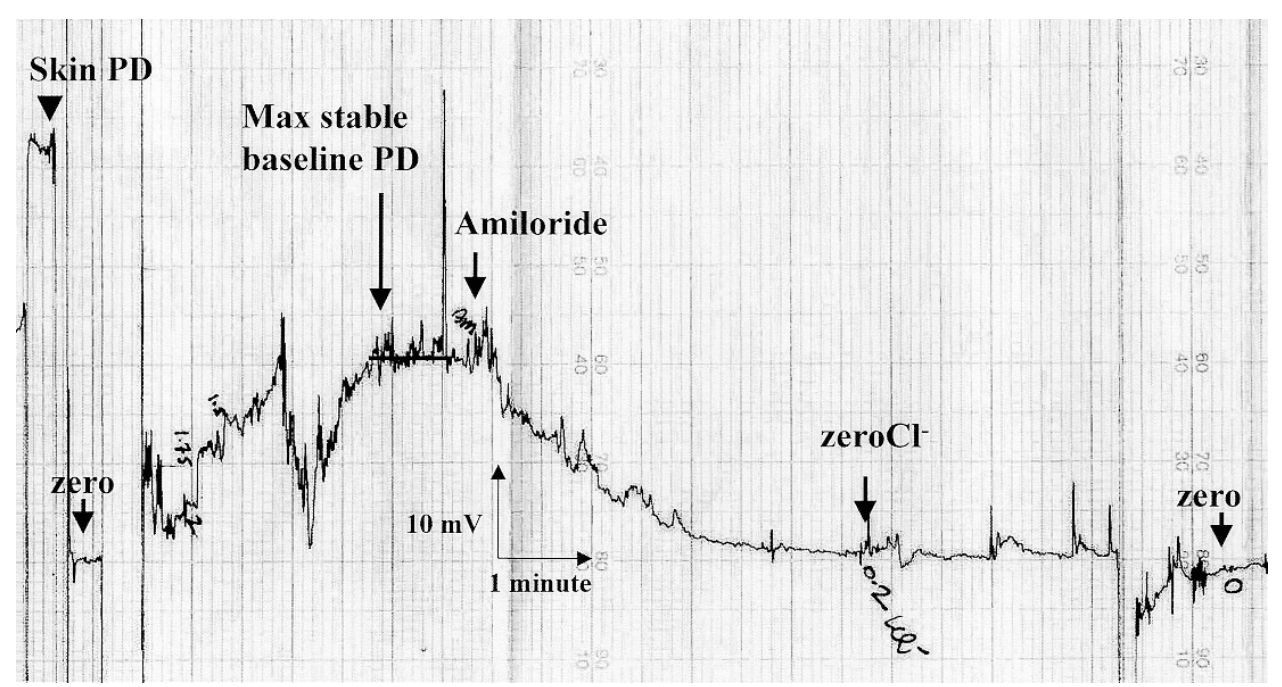

Figure 1. PD tracing from a 38-wk gestation infant, vaginal delivery, $22 \mathrm{~h}$ old. After checking zero and skin PD, the maximal stable baseline PD was identified $(-22 \mathrm{mV})$. Amiloride perfusion $(0.1 \mathrm{~mL} / \mathrm{min})$ was then commenced, and $\mathrm{PD}$ fell by $21 \mathrm{mV}$ to $-1 \mathrm{mV}$. There was no change in $\mathrm{PD}^{-}$after zero-Cl ${ }^{-}$perfusion at $0.2 \mathrm{~mL} / \mathrm{min}$. Zero was rechecked at completion of the study.

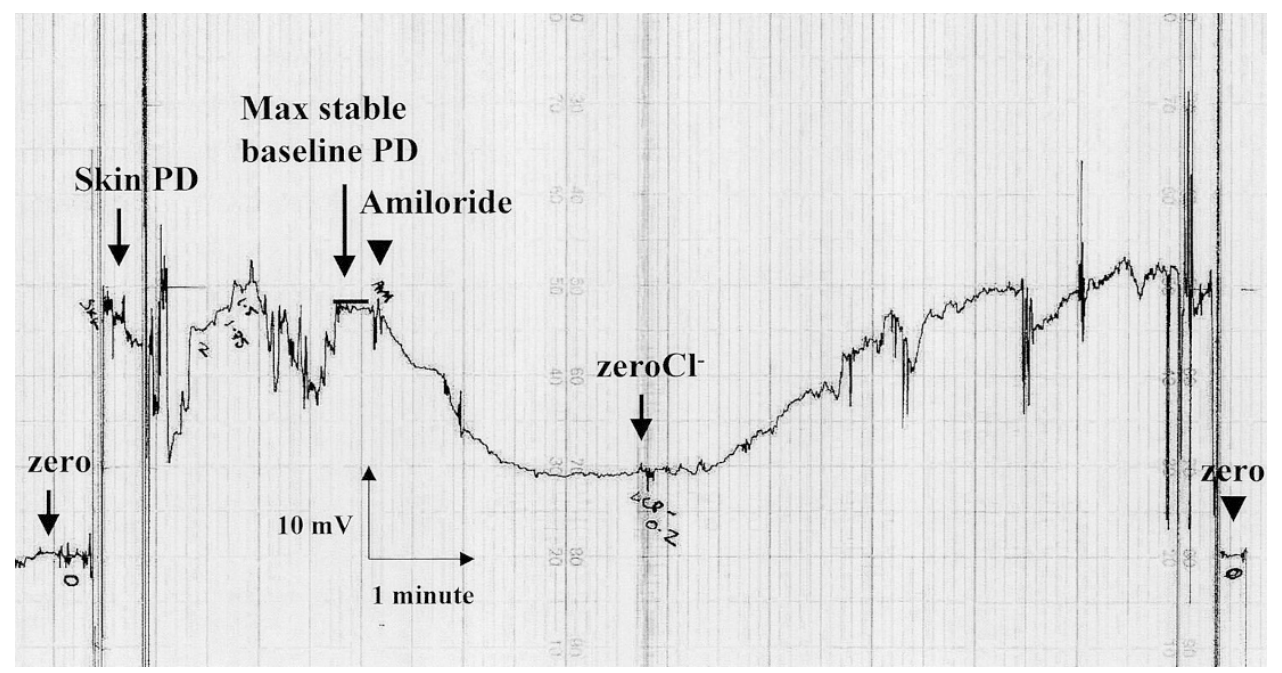

Figure 2. PD tracing from a 39-wk infant, elective cesarean section, $5 \mathrm{~h}$ old. Maximal stable baseline $\mathrm{PD}$ was $-28 \mathrm{mV}$. After amiloride perfusion $0.1 \mathrm{~mL} / \mathrm{min}$ $\mathrm{PD}$ fell to $-9 \mathrm{mV}$. There was a marked response to perfusion with zero- $\mathrm{Cl}^{-}$solution $(0.2 \mathrm{~mL} / \mathrm{min})$, with $\Delta$ zero $\mathrm{Cl}^{-}$of $-23 \mathrm{mV}$.

may reflect more advanced lung fluid clearance in some infants compared with others; however, all these infants were well.

There are a number of methodological differences that may account for the disparity between our results and those of Gowen et al. (21). We used a perfusion protocol modified and validated for use in infants with lower perfusion rates (18). Using this method we were able to obtain high-quality recordings. We found the technique was well tolerated; however, infants would occasionally become unsettled during the second nostril measurement, giving less satisfactory recordings. For the analysis we used only results from the first nostril recording. Despite low perfusion rates, fluid could be detected in both nostrils during the first nostril recording, giving rise to the possibility of amiloride contamination in the second nostril. (This was most obvious in cases in which PDs were high). Comparison of maximal stable baseline PD values between the nostrils using the technique described by Bland and Altman (22) confirmed this clinical suspicion, and although the differ- ence did not reach statistical significance, we decided not to include second nostril data in the analysis.

We have not calculated a mean PD. Maximal stable PD is, in our opinion, a more valid and reproducible measure to describe the level of $\mathrm{ENaC}$ activity. In the study by Gowen et al. (21) the use of mean PD or mean maximal PD did not alter the conclusions from the study.

Finally, we demonstrated much greater responses to perfusion with amiloride than Gowen et al. (21), and this may reflect the higher concentration of amiloride used in our study $\left(10^{-4} \mathrm{M}\right.$ versus $\left.10^{-5} \mathrm{M}\right)$. Our dose of amiloride was derived from previous work demonstrating a further reduction in PD when changing from $10^{-5} \mathrm{M}$ to $10^{-4} \mathrm{M}$ (18). In addition to the methodological disparities, the infants in our study were all well, and their ion transport phenotypes may reflect this. Indeed our findings are not at odds with the hypothesis that ENaC-mediated $\mathrm{Na}^{+}$absorption is primed by catecholamines, as previous studies have demonstrated 
similar catecholamine levels in infants born with or without labor (27).

There were significant differences between our two cohorts with respect to gestation and time of measurement, related to logistical considerations (all elective cesarean sections were performed at $38 \mathrm{wk}$ and their measurements were performed in the afternoon after delivery in the morning). These are potentially important confounding variables. There is evidence for a gestation-dependent increase in EnaC; however, this relates to subunit (8) or subunit-encoding mRNA levels (9) rather than functional studies. There are to our knowledge no reported data from clinical studies on $\mathrm{ENaC}$-mediated $\mathrm{Na}^{+}$transport in moderately preterm infants greater than $30 \mathrm{wk}$ gestation. When comparing our data to PDs reported by Gowen et al. (21), the difference in baseline PD in the no labor cohorts is relatively small. We did, however, find higher maximal stable baseline PDs in the cohort of infants who experienced normal labor.

Timing of the nasal PD measurement may also have influenced our results. There was, however, no correlation between maximal stable baseline PD and postnatal age in hours; these data are consistent with the findings of Gowen et al. (21).

This is the first report of nasal PD measurements assessing the capacity for $\mathrm{Cl}^{-}$secretion in infants. The median response of $\mathrm{PD}$ to perfusion with zero- $\mathrm{Cl}^{-}$solution was low in both cohorts of infants. Nasal PD protocols designed for older children and adults use a further zero- $\mathrm{Cl}^{-}$solution with the addition of a $\beta$-adrenergic agonist such as isoproterenol. This results in further cAMP-mediated $\mathrm{Cl}^{-}$secretion. Isoproterenol was omitted from our protocol because of concerns of systemic effects in infants. Perfusion with a zero- $\mathrm{Cl}^{-}$solution is associated with sustained hyperpolarization of $\mathrm{PD}$, generally with a change in PD of greater than $-10 \mathrm{mV}$. Knowles et al. (17) in 72 studies involving subjects with an age range from 1 to $70 \mathrm{y}$ found a mean change in PD after zero- $\mathrm{Cl}^{-}$solution of -18.0 $\mathrm{mV}$ (range, 0 to $-40 \mathrm{mV}$ ).

Some infants in our study did demonstrate a capacity to secrete $\mathrm{Cl}^{-}$; however, the median response of -1.0 (no labor) and $-2.5 \mathrm{mV}$ (normal labor), respectively, suggests that $\mathrm{Cl}^{-}$ secretion is not a significant ion transport process in infants shortly after birth. $\mathrm{As} \mathrm{Cl}^{-}$channel expression is not reduced at birth, this finding possibly reflects active down-regulation of $\mathrm{Cl}^{-}$transport on the first postnatal day.

In contrast, maximal stable baseline PDs were often high, and $\Delta$ amil was large [median $\%$ inhibition in PD magnitude, $83.5 \%$ (no labor) and $79.0 \%$ (normal labor)]. Indeed, one infant fulfilled predetermined criteria to screen for cystic fibrosis (a condition characterized by airway ion transport abnormalities; namely $\mathrm{Na}^{+}$hyperabsorption and lack of $\mathrm{Cl}^{-}$secretory capacity). The infant did not have clinical features suggestive of cystic fibrosis, and subsequent sweat electrolyte analysis was normal (28).

\section{CONCLUSIONS}

In summary, this study does convincingly demonstrate that, on the first day of postnatal life, well term infants have an ion transport profile that is predominantly absorptive, with welldeveloped $\mathrm{ENaC}$-mediated $\mathrm{Na}^{+}$absorption and a reduced ca- pacity for $\mathrm{Cl}^{-}$secretion. This study does not support the hypothesis that infants born without labor have reduced $\mathrm{ENaC}$ mediated $\mathrm{Na}^{+}$transport on the first day of postnatal life if they are well.

Acknowledgments. The authors thank the families who supported this project. We also thank Dr. Pierre Barker, University of North Carolina at Chapel Hill, who was the driving force behind the development of this infant nasal PD system, and the staff on the Neonatal Intensive Care Unit at the Liverpool Women's Hospital for their support.

\section{REFERENCES}

1. Olver RE, Strang LB 1974 Ion fluxes across the pulmonary epithelium and the secretion of lung liquid in the foetal lamb. J Physiol (Lond) 241:327-357

2. Kitterman JA, Ballard PL, Clements JA, Mescher EJ, Tooley WH 1979 Tracheal fluid in fetal lambs: spontaneous decrease prior to birth. J Appl Physiol 47:985-989

3. Brown MJ, Olver RE, Ramsden CA, Strang LB, Walters DV 1983 Effects of adrenaline and of spontaneous labour on the secretion and absorption of lung liquid in the fetal lamb. J Physiol (Lond) 344:137-152

4. Bland RD 1990 Lung epithelial ion transport and fluid movement during the perinatal period. Am J Physiol 259:L30-L37

5. Canessa CM, Schild L, Buell G, Thorens B, Gautschi I, Horisberger JD, Rossier BC 1994 Amiloride-sensitive epithelial $\mathrm{Na}^{+}$channel is made of three homologous subunits. Nature 367:463-467

6. Renard S, Voilley N, Bassilana F, Lazdunski M, Barbry P 1995 Localization and regulation by steroids of the alpha, beta and gamma subunits of the amiloridesensitive $\mathrm{Na}^{+}$channel in colon, lung and kidney. Pflugers Arch: Eur J Physiol 430:299-307

7. McDonald FJ, Price MP, Snyder PM, Welsh MJ 1995 Cloning and expression of the beta- and gamma-subunits of the human epithelial sodium channel. Am J Physiol 268:C1157-C1163

8. Smith DE, Otulakowski G, Yeger H, Post M, Cutz E, O’Brodovich HM 2000 Epithelial $\mathrm{Na}(+)$ channel $(\mathrm{ENaC})$ expression in the developing normal and abnormal human perinatal lung. Am J Respir Crit Care Med 161:1322-1331

9. Tchepichev S, Ueda J, Canessa C, Rossier BC, O’Brodovich H 1995 Lung epithelial $\mathrm{Na}$ channel subunits are differentially regulated during development and by steroids. Am J Physiol 269:C805-C812

10. Hummler E, Barker P, Gatzy J, Beermann F, Verdumo C, Schmidt A, Boucher R, Rossier BC 1996 Early death due to defective neonatal lung liquid clearance in alpha-ENaC-deficient mice. Nat Genet 12:325-328

11. Schild L, Schneeberger E, Gautschi I, Firsov D 1997 Identification of amino acid residues in the alpha, beta, and gamma subunits of the epithelial sodium channel $(\mathrm{ENaC})$ involved in amiloride block and ion permeation. J Gen Physiol 109:15-26

12. O'Brodovich H, Hannam V, Seear M, Mullen JB 1990 Amiloride impairs lung water clearance in newborn guinea pigs. J Appl Physiol 68:1758-1762

13. Berger PJ, Smolich JJ, Ramsden CA, Walker AM 1996 Effect of lung liquid volume on respiratory performance after caesarean delivery in the lamb. J Physiol (Lond) 492:905-912

14. Olver RE 1981 Of labour and the lungs. Arch Dis Child 56:659-662

15. Olver RE, Ramsden CA, Strang LB, Walters DV 1986 The role of amilorideblockable sodium transport in adrenaline-induced lung liquid reabsorption in the fetal lamb. J Physiol (Lond) 376:321-340

16. Walters DV, Olver RE 1978 The role of catecholamines in lung liquid absorption at birth. Pediatr Res 12:239-242

17. Knowles MR, Paradiso AM, Boucher RC 1995 In vivo nasal potential difference: techniques and protocols for assessing efficacy of gene transfer in cystic fibrosis. Hum Gene Ther 6:445-455

18. Southern KW, Noone PG, Bosworth DG, Legrys VA, Knowles MR, Barker PM 2001 A modified technique for measurement of nasal transepithelial potential difference in infants. J Pediatr 139:353-358

19. Knowles MR, Carson JL, Collier AM, Gatzy JT, Boucher RC 1981 Measurements of nasal transepithelial electric potential difference in normal human subjects in vivo. Am Rev Respir Dis 124:484-490

20. Knowles MR, Buntin WH, Bromberg PA, Gatzy JT, Boucher RC 1982 Measurements of transepithelial electric potential differences in the trachea and bronchi of human subjects in vivo. Am Rev Respir Dis 126:108-112

21. Gowen CW, Lawson EE, Gingras J, Boucher RC, Gatzy JT, Knowles MR 1988 Electrical potential difference and ion transport across nasal epithelium of term neonates: correlation with mode of delivery, transient tachypnea of the newborn, and respiratory rate. J Pediatr 113:121-127

22. Bland JM, Altman DG 1999 Measuring agreement in method comparison studies. Stat Methods Med Res 8:135-160

23. Morrison JJ, Rennie JM, Milton PJ 1995 Neonatal respiratory morbidity and mode of delivery at term: influence of timing of elective caesarean section. $\mathrm{Br} \mathrm{J}$ Obstet Gynaecol 102:101-106

24. Avery ME, Gatewood OB, Brumley G 1966 Transient tachypnea of newborn. Possible delayed resorption of fluid at birth. Am J Dis Child 111:380-385 
25. Milner AD, Saunders RA, Hopkin IE 1978 Effects of delivery by caesarean section on lung mechanics and lung volume in the human neonate. Arch Dis Child 53:545-548

26. Barker PM, Gowen CW, Lawson EE, Knowles MR 1997 Decreased sodium ion absorption across nasal epithelium of very premature infants with respiratory distress syndrome. J Pediatr 130:373-377
27. Faxelius G, Hagnevik K, Lagercrantz H, Lundell B, Irestedt L 1983 Catecholamine surge and lung function after delivery. Arch Dis Child 58:262-266

28. Gaillard EA, Shaw NJ, Wallace HL, Subhedar NV, Southern KW 2002 Employing the nasal potential difference as a diagnostic test for cystic fibrosis in neonates: potential pitfalls. J Pediatr 141:295-296

\section{Erratum}

In the article, "Effects of Dietary Sphingomyelin on Central Nervous System Myelination in Developing Rats" (Pediatr Res 53:589-593), a few corrections were not made to the final proof. They are listed below. The publisher regrets the error.

1. Last sentence in the "ABSTRACT" should read

These findings suggest that dietary SM contributes to CNS myelination in developing rats with experimental inhibition of SPT activity.

2. Correspondence:

Kyoichi Oshida, Ph.D

3. "Study design." in the "METHODS" (right column, line 11)

s.c. injection of LCS (100 mg/kg; Sigma-Aldrich Japan K.K., Tokyo, Japan)

4. "Morphometric analysis of optic nerve myelination." in the "METHODS" just above Equation 1

The axon area was obtained from the digitized axon perimeter using NIH Image v.1.61 software

5. "Morphometric analysis of optic nerve myelination." in the "METHODS" just after Equation 1

The fiber area was obtained using NIH Image software to detect the digitized outermost major dense line of the myelin sheath...

6. Last footnote in Table 2

For the LCS group, values in parenthesis indicate the percent decreases relative to the non-LCS group. 